\title{
RESENHA
}

\section{SCHMITT, Norbert. Researching vocabulary - A vocabulary research manual. Série: CANDLIN, Christopher N. e HALL, David R. (Ed.). Research and practice in applied linguistics. Hampshire: Palgrave Macmillan, 2010. $386 \mathrm{p}$.}

\section{"Pesquisa em Vocabulário": uma contribuição única para o campo de estudos lexicais}

A principal contribuição da mais recente publicação de Norbert Schmitt - Researching vocabulary - A vocabulary research manual (Pesquisa em vocabulário - um manual de pesquisa em vocabulário) - é oferecer um guia tão completo quanto atualizado a estudiosos e profissionais envolvidos na pesquisa sobre ensinoaprendizagem e aquisição de vocabulário na língua materna (L1) e, especialmente, na língua estrangeira (L2). Dada a importância do léxico para o desenvolvimento pleno das habilidades linguísticas de qualquer falante, pode-se dizer que não se trata de colaboração pequena.

Schmitt faz parte de um seleto grupo de pesquisadores que não somente informa sobre diferentes abordagens de pesquisa em vocabulário, mas também desenvolve e aprimora continuamente suas próprias abordagens. Essa particularidade, registrada em diversos trabalhos produzidos pelo autor, incluindo coedições e publicações de livros (Vocabulary in Language Teaching, 2000, e Formulaic Sentences: Acquisition, processing and use, 2004) responde - se não unicamente, ao menos em grande parte - pela harmonia na distribuição dos temas tratados ao longo do texto, como também pelo uso de uma linguagem simples e, ao mesmo tempo, eficaz o suficiente para explicar, por exemplo, cálculos estatísticos utilizados na metodologia de pesquisa quantitativa e o funcionamento de estudos lexicais através de neuroimagens funcionais por ressonância magnética (fMRI).

O livro é organizado em quatro partes. A primeira delas, intitulada "Panorama de Questões referentes a Vocabulário", tem como objetivo apresentar o que já se sabe sobre a pesquisa lexical, para, a partir disso, chegar ao objetivo primeiro do manual - i.e., oferecer uma base sólida da metodologia de pesquisa na área.
Em seu panorama, Schmitt (i) aborda dez temas centrais para o uso e aquisição de vocabulário - entre os quais estão forma das palavras, linguagem formulaica, complexidade e continuidade do processo de aquisição lexical, retenção lexical de longo prazo, importância da L1 nos estudos lexicais na L2 e avanços da pesquisa lexical pela análise de corpus -, (ii) retoma a relação entre vocabulário e leitura e (iii) apresenta uma amostra de lacunas de conhecimento no campo de estudos lexicais.

Esses tópicos são retomados, e alguns expandidos, na Parte 2, "Bases para a Pesquisa sobre Vocabulário", mas o foco agora está no tratamento de cada um deles na pesquisa lexical. Como ilustração, voltemo-nos a um dos temas discutidos na primeira parte da obra, os diferentes níveis de conhecimento de uma palavra - parcial ou total, receptivo ou produtivo. Sobre isso, Schmitt afirma que "pesquisas futuras precisam ser mais claras com relação aos aspectos do domínio receptivo e produtivo sob análise" (p. 89), já que o cenário atual é o uso predominante de testes de reconhecimento de significado de palavras, o que significa que

o conhecimento e a força de aquisição do vocábulo que reportam concentram-se nos estágios iniciais de aprendizado em termos de profundidade de conhecimento, e provavelmente também em termos de automaticidade e integração lexical (p. 89, tradução nossa).

O assunto que recebe maior atenção do autor nessa parte da obra é o papel da linguagem formulaica na aquisição de vocabulário, com um capítulo inteiro dedicado ao tema (Cap. 3). Inicialmente buscando mostrar por que há tantos termos para tratar de um mesmo fenômeno, Schmitt avança descrevendo estudos realizados com softwares de análise de corpus (concordancers) e enfatizando o importante papel desses na pesquisa lexical 
em língua materna e/ou estrangeira. $\mathrm{O}$ fechamento do capítulo é instigante para qualquer estudioso da área, com o levantamento de questões que ainda não foram investigadas, como, por exemplo: (i) o que é semelhante/ diferente na aquisição de sequências formulaicas em contextos naturais e formais?; (ii) qual é a relação entre o conhecimento dessas sequências e o conhecimento das palavras que a compõem?; (iii) que elementos de uma sequência formulaica são mais salientes no processo de aquisição?

As duas últimas seções do manual, 3 e 4 - "Pesquisa em Vocabulário" e "Recursos", respectivamente -, são, sem dúvida, as principais. Na parte 3, subdividida em três capítulos, o leitor encontra esclarecimentos sobre como conduzir pesquisas quantitativas na área lexical, com a disponibilização de instrumentos de medição de vocabulário e de exemplos de projetos de pesquisa. Com relação à pesquisa qualitativa especificamente, a autor lembra que, embora não seja o foco do seu trabalho, não se pode minimizar seu valor, dado que a prática corrente "usa medidas múltiplas para triangular resultados de mais de uma abordagem, a fim de obter achados mais robustos" (p. 149).

No Capítulo 4, os esclarecimentos relativos a questões centrais na pesquisa sobre vocabulário cobrem uma variedade respeitável de temas, como (i) seleção de participantes, incluindo número ideal e características individuais que devem ser controladas durante o estudo; (ii) necessidade de medidas múltiplas de vocabulário que permitam afirmar em que nível uma palavra é de fato conhecida, como também de testes longitudinais e de pós-testes; e (iii) seleção criteriosa dos itens lexicais alvo, a fim de garantir o equilíbrio entre esses e os objetivos da pesquisa.

Nesse contexto, o Capítulo 5 oferece soluções para lidar com essas questões, com testes e fórmulas que permitem obter diferentes medidas de conhecimento de vocabulário, como conhecimento lexical pré-existente, conhecimento lexical receptivo, conhecimento lexical produtivo e qualidade do conhecimento lexical. O autor apresenta ainda métodos para medir a frequência de ocorrência de itens lexicais, como o Lexical Frequency Profile de Heatley, Nation e Coaxhead (2002), e para classificar a natureza do conhecimento lexical associativo, como as categorias de Fitzpatrick (2006) para as respostas de associação de palavras.

Continuamente relembrando todos os fatores envolvidos no conhecimento genuíno de uma palavra, o que demanda testes acurados e completos para avaliá-lo, Schmitt finaliza o capítulo com a apresentação de uma bateria de testes desenvolvida por Webb $(2005,2007$ a 2007b) e assinala que, com elas, o linguista consegue "levar a noção de medidas multicomponenciais e concorrentes de vocabulário a um novo nível” (p. 238). A bateria prevê dez testes, com medidas de vocabulário receptivo e produtivo, relação forma-significado, funções gramaticais, colocações (collocations) e associações lexicais.

Encerrando a parte dedicada especificamente à pesquisa lexical, no Capítulo 6 são apresentados dez exemplos de projetos elaborados para pesquisadores com menos experiência desenvolverem suas habilidades. A orientação de Schmitt envolve todas as etapas da realização de um estudo, desde a definição dos objetivos até a análise dos resultados, com especial atenção para a metodologia, como seria esperado. Ainda que esse capítulo possa ser dispensável para estudiosos do léxico com mais experiência em pesquisa quantitativa, ele é certamente um alento para os que se iniciam na área, especialmente após o encontro com tantas fórmulas estatísticas e testes de estimativas de vocabulário no capítulo precedente.

A última seção do livro, denominada simplesmente de "Recursos" e composta por um único capítulo, é de grande utilidade para pesquisadores iniciantes, e provavelmente também será para profissionais da área com mais conhecimento de causa. Vários instrumentos de aferição lexical, diferentes tipos de corpora em diversas línguas (incluindo o Corpus do Português, CdP, com textos de Portugal e do Brasil), concordancers e listas de vocabulário disponíveis gratuitamente são descritos, com a indicação do título do artigo em que se encontram e/ou a página da internet em que estão depositados. Além disso, o autor ainda menciona sites construídos por eminentes pesquisadores na área de aquisição lexical, sites com bibliografias relevantes para áreas específicas de estudos lexicais e nomes de personagens importantes no campo de estudos do vocabulário. Ao todo, Schmitt seleciona 57 nomes, subdivididos entre pesquisadores voltados para a aquisição de vocabulário em L2, na qual ele se enquadra; e pesquisadores voltados para estudos lexicais de modo geral.

Assim, levando em consideração nossa descrição em termos de objetivos, organização do texto e tratamento das questões relativas à pesquisa em vocabulário, não vemos qualquer outro modo coerente de concluir esse texto a não ser recomendar a leitura desse manual por estudantes de pós-graduação e profissionais que tenham como área de interesse os estudos lexicais. Ainda que a maioria dos dados apresentados pelo autor seja relativa à aquisição de vocabulário em língua estrangeira, há muita informação que pode ser aproveitada igualmente para a língua materna. Na verdade, é nessa peculiaridade - um número precioso de informação atualizada e de excelente qualidade - que se encontra o grande mérito da nova obra de Norbert Schmitt. 


\section{Referências}

HEATLEY, Dave; NATION, Paul; COXHEAD, Averil. Software Range, 2002. Disponível em: <http:www.victoria.ac.nz.lals/ staff/paul-nation/nation.aspx>. Acesso em: 11 ago. 2012.

FITZPATRICK, Tess. Rabits and Habbits: Word associations and the L2 lexicon. EUROSLA Yearbook, v. 6, p. 121-45, 2006.

SCHMITT, Norbert. Vocabulary in Language Teaching. Cambridge: Cambridge University Press, 2000.

SCHMITT, Norbert. Formulaic sentences: Acquisition, processing and use. Amsterdan: John Benjamins, 2004.

WEBB, Stuart. Receptive and productive vocabulary learning: The effects of reading and writing on Word knowledge. Studies in Second Language Acquisition, v. 27, p. 33-52, 2005.
WEBB, Stuart. Learning word pairs and glossed sentences: The effects of a single context on vocabulary knowledge. Language Teaching Research, v. 11, n. 1, p. 63-81, 2007a.

WEBB, Stuart. The effects of repetition on vocabulary knowledge. Applied Linguistics, v. 28, n. 1, p. 46-65, $2007 \mathrm{~b}$.

Alessandra Baldo

Universidade Federal de Pelotas

Recebido: 24 de agosto de 2012

Aprovado: 25 de novembro de 2013

Contato: alessabaldo@gmail.com 